Bangladesh J. Bot. 39(1): 21-28, 2010 (June)

\title{
EFFECTS OF AGE ON THE SURVIVAL AND RECOVERY OF SUBMERGED RICE (ORYZA SATIVA L.) SEEDLINGS
}

\author{
M. S. Pervin*, A. R. Gomosta AND J. U. Ahmed ${ }^{1}$ \\ Plant Physiology Division, Bangladesh Rice Research Institute, Gazipur, Bangladesh
}

Key words: Rice, T. Aman, Carbohydrate content, Seedling age, Survival, Recovery

\begin{abstract}
Post-submergence (about $100 \mathrm{~cm}$ water depth for ten days) survivality and recovery of rice seedlings were studied in a greenhouse experiment. Irrespective of varieties, 10 and 15-day-old seedlings barely could recover from the shock. More than $80 \%$ of 20-day-old seedlings of variety FR13A survived. With the increase of seedling age, elongation of plants decreased during submergence. The variety FR13A and BRRI dhan32 recovered considerably at the seedling age exceeding 20-day, whereas BR6110-10-2-1 and BR11 performed the same not below 40-day-old seedlings. At the higher seedling age, all the varieties maintained higher level of soluble sugar and starch both before and after submergence. During the submergence, the depletion rate of soluble sugar was more or less similar in all the varieties, but the rate of starch depletion was the lowest in FR13A. Therefore, the amount of total carbohydrate both pre- and post-submergence was higher in tolerant variety FR13A that might contribute to the better survivality and recovery ability.
\end{abstract}

\section{Introduction}

Rainfed, lowland rice transplanting aman covers an area of 4.5 million hectares in Bangladesh (Islam et al.1997) during June-September. As a result the crop is often submerged by flash flood as well as onrush of flood water. Such flood may continue for a week or more. Resulting severe decrease in yield (Zeigler and Puckridge 1995). Sarkar et al. (2006) reported that flash- flooding and submergence adversely affect at least $16 \%$ of the rice lands of the world (= $22 \mathrm{~m} \mathrm{ha})$. Sometimes it causes total crop failure. So, flooding is an important constraint in T. Aman rice. Submergence tolerance and recovery ability both are equally important for lowland T. Aman rice. Moreover, submergence tolerance and recovery ability is affected by turbidity, water temperature, duration of submergence, solar radiation, and plant characters like seedling age, seedling quality, etc. (Ito et al. 1999, Sauter 2000). Pande et al. (1979) reported that grain yield of rice increased with the increase of seedling age in intermittent flooded area.

Older seedlings, which have greater submergence tolerance, also contain more carbohydrate (Chaturvedi et al. 1993). The tolerant varieties are able to retain their stored carbohydrate which is used during the recovery period. The susceptible varieties cannot either produces enough carbohydrate to store or cannot retain their carbohydrate and, therefore, cannot recover until the period of submergence is over.

The present study was undertaken to find out the contribution of seedling age as well as reserved carbohydrate on the survival and recovery of submerged seedlings and identify the most tolerant varieties of T. Aman.

\section{Material and Methods}

The experiment was conducted in the greenhouse of Plant Physiology Division, Bangladesh Rice Research Institute (BRRI) during T. Aman season, 2004. Three varieties (FR13A, BR11 and BRRI dhan32) and an advanced breeding line (BR6110-10-2-1) were used. Uniformly sprouted

*Corresponding author. Email: pervinsalma@yahoo.com ${ }^{1}$ Crop Botany Department, Bangabandhu Sheikh Mujibur Rahman Agricultural University, Gazipur, Bangladesh. 
seeds of these entries were sown in lines in steel trays having dimensions of $50 \mathrm{~cm} \times 40 \mathrm{~cm} \times 15$ $\mathrm{cm}$ containing soil. The soil was thoroughly puddled and fertilized with Urea-TSP-MP-gypsum at the rate of 5-2-2-2 g/tray before sowing (equivalent to $120-80-60-60 \mathrm{~kg} / \mathrm{ha}$ ). Thinning was done after seven days of seeding for keeping desired density of plants having same leaf stage. To produce seedlings of various ages, sowing was done at five days interval up to 45 days seedlings. These seedlings were submerged completely at a depth of $100 \mathrm{~cm}$ in a cemented water-tank (submergence tank). The water was made turbid twice daily by mixing mud to mimic natural turbid flood water. The water had soil particles of $1.53 \mathrm{~g} / \mathrm{l}$. After ten days of submergence, the trays were transferred to the greenhouse and plants were allowed to recover for 30 days. At 15 days after the drainage of water, $2 \mathrm{~g}$ of urea was applied in each tray. The experiment was laid out in factorial completely randomized design having two factors with four replications. The elongation ability was recorded at the end of submergence following Hossain et al. (1983). The rate of survival was measured after 15 days of drainage of water following Supapoj et al. (1979). The submergence tolerance score was recorded after five days of drainage of water (Hossain et al. 1983). Scoring for submergence tolerance was made based on the phenotypic appearance of the seedlings following Gomosta et al. (1982). The lower score indicated higher tolerance and vice versa. Recovery score was recorded in terms of growth vigor and tiller number per hill at 30 days after termination of submergence treatment (Supapoj et al.1979). Carbohydrate content in the plants was analyzed at both before and after submergence. Method of extraction and measurement of sugar and starch were done following the anthrone methods as described by Yoshida et al. (1976).

Data were analyzed statistically following ANOVA, LSD and CV \%. For sugar and starch only mean values were used.

\section{Results and Discussion}

Survival percentage increased with the increase of seedling age (Fig. 1). Among the varieties, FR13A had the highest survival percentage followed by BRRI dhan32. In FR13A, ten and 15-day old seedlings died, while 20-day old seedlings survived more than $80 \%$. These results are in partial agreement with Hossain et al. (1983) who observed that FR13A was an exception having high tolerance to submergence at all ages. No seedlings up to 20 days of the other three varieties (BR6110-10-2-1, BR11, and BRRI dhan32) could survive. Moreover, these three varieties could

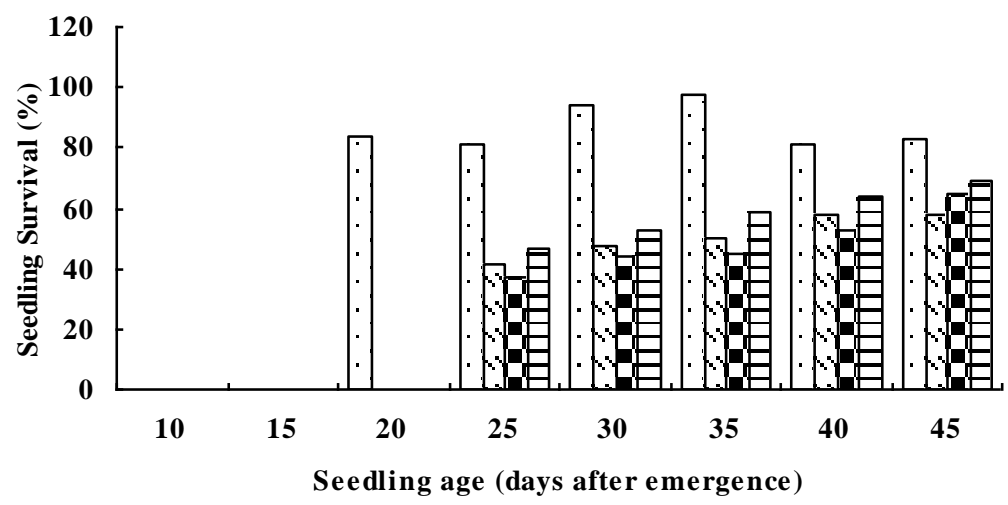

Fig. 1. Per cent survival of the seedlings affected by submergence in four rice varieties of different seedling ages. (ㅁ FR13A, øBR6110-10-2-1, . BR11 and $\square$ BRRI dhan32). 
not exceed their survival ability of $46 \%$ even in 25 -day old seedlings. In contrast, FR13A maintained its performance at more than $80 \%$. In FR13A, the per cent survival fluctuated but did not fall below 80 . The survival rate of the remaining three varieties was below $80 \%$ even in 45 -day old seedling.

The other workers reported that most rice cultivars cannot survive complete submergence for a long time, more so, during the early stage of development. The experiments conducted at NDUAT and elsewhere indicate that 45-day-old seedlings showed better tolerance to submergence (7, 11 and 15 days submergence) than 30 or 15-day old seedlings with high genetic variability (Chaturvedi et al. 1993, Mazaredo and Vergara 1982).

Table 1. Submergence tolerance score of four rice varieties as affected by seedling age.

\begin{tabular}{|c|c|c|c|c|c|c|c|c|}
\hline \multirow{2}{*}{ Variety } & \multicolumn{8}{|c|}{ Seedling age (days) } \\
\hline & 10 & 15 & 20 & 25 & 30 & 35 & 40 & 45 \\
\hline FR13A & 9.0 & 9.0 & 1.0 & 1.0 & 1.0 & 1.0 & 1.0 & 1.0 \\
\hline BR6110-10-2-1 & 9.0 & 9.0 & 9.0 & 6.0 & 5.5 & 4.5 & 2.5 & 2.5 \\
\hline BR11 & 9.0 & 9.0 & 9.0 & 5.5 & 7.0 & 5.5 & 4.0 & 3.5 \\
\hline BRRI dhan32 & 9.0 & 9.0 & 9.0 & 4.5 & 4.7 & 3.0 & 2.5 & 2.3 \\
\hline $\operatorname{LSD}(1 \%)$ & \multicolumn{8}{|c|}{2.3} \\
\hline $\mathrm{CV}(\%)$ & \multicolumn{8}{|c|}{24.1} \\
\hline
\end{tabular}

Irrespective of variety, submergence tolerance increased significantly with the increase of seedling age as indicated by lower submergence tolerance score (Table 1). This was perhaps due to the accumulation of higher quantity of pre-submergence dry matter content in older seedlings (Fig. 2). Among the tested varieties, FR13A had significantly the highest degree of tolerance to submergence at any age. The other varieties, achieved same level of tolerance to submergence when seedlings used beyond 35-day old. Up to 35-day old seedling BR6110-10-2-1 scored not less than 4.5. At 40 and 45-day old seedling, it performed better. In case of BR11, tolerance increased with the increase of seedling age but scores were not less than 3.5 across age. The variety BRRI dhan32 scored 3 or less at 35 days and above, respectively. Adkins et al. (1988) reported that submergence sensitivity of plants varied with age, with younger ones more sensitive than older ones.

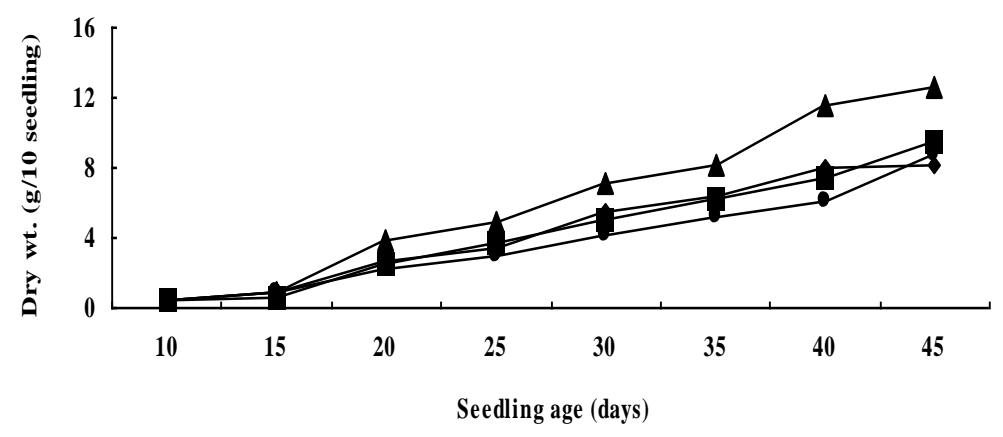

Fig. 2. Pre-submergence dry matter accumulated in seedlings at different ages. (- $\mathbf{\Delta}$-FR13A - - BR11, - BR6110-10-2-1, -m- BRRI dhan32).

The dry matter accumulation pattern was found to be quite variable among the varieties of rice (Fig. 2). Up to 15-day of seedling age, the seedling dry matter did not differ clearly. 
Thereafter, FR13A showed the highest dry matter yield compared to all other varieties. The seedling survival starting 20-day of seedling age in the FR13A and concomitantly the highest seedling dry matter at the same seedling age indicated that the submergence tolerance of the variety was somehow contributed by the seedling age in rice.

Plant ability to elongate during submergence was expressed as per cent of pre-submergence height (Fig. 3B). Results indicate that in FR13A elongation was maximum in 20-day-old seedling which afterwards decreased gradually. The highest elongation in other varieties was recorded in 25-day-old seedling and followed a declining trend in subsequent stages. But the magnitude of elongation was smaller in FR13A relative to the other varieties. The plant height of older seedling before submergence was high (Fig. 3A) and the elongation tendency of taller plant was low. It is clear here that larger elongation rate had the lesser contribution to submergence tolerance and vice versa. The high quality seedlings in terms of seedling height, dry matter, and seedling strength (dry matter per unit seedling length) reduced the elongation ability as well as susceptibility to submergence. It was also reported that the high quality seedling of FR13A had zero to negligible elongation ability (BRRI 1984).
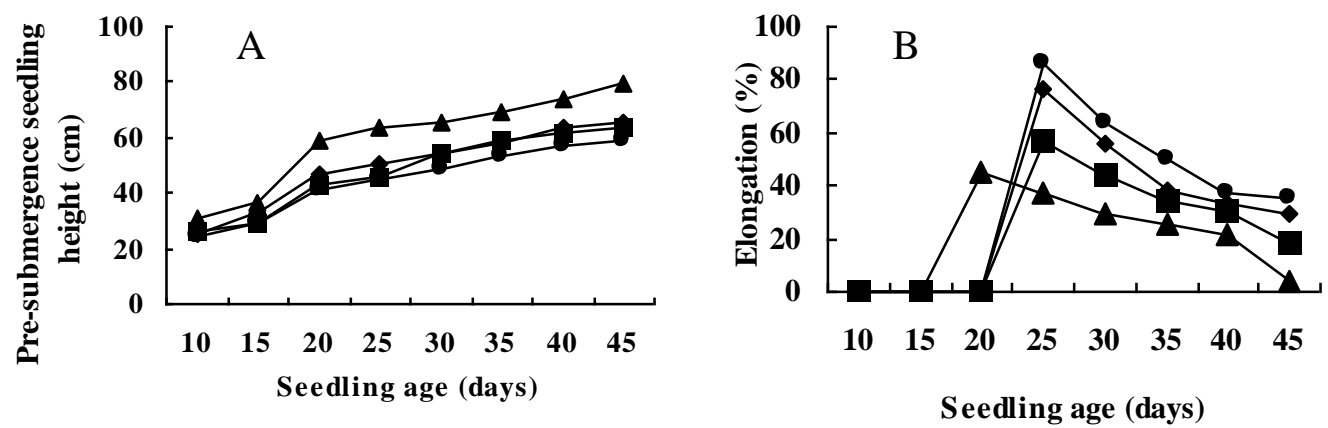

Fig. 3. Pre-submergence seedling height (A) and elongation (B) in four rice varieties as affected by seedling

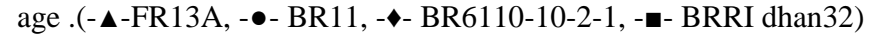

Irrespective of variety, the seedling with a higher age produced more tillers during recovery period after submergence (Table 2). The variety FR13A and BRRI dhan32 produced different number of tillers at different seedling ages but the differences were not significant at any age. But BR6110-10-2-1 and BR11 produced the higher tiller at the maximum seedling age compared to any earlier stages.

Table 2. Number of tillers/line at $\mathbf{3 0}$ days after drainage of water as affected by seedling age in four rice varieties.

\begin{tabular}{lcccccccc}
\hline Varieties & \multicolumn{7}{c}{ Seedling age (days) } \\
\cline { 2 - 9 } & 10 & 15 & 20 & 25 & 30 & 35 & 40 & 45 \\
\hline FR13A & - & - & 38.0 & 34.8 & 44.8 & 39.8 & 57.8 & 47.0 \\
BR6110-10-2-1 & - & - & - & 17.0 & 23.0 & 17.8 & 18.0 & 29.3 \\
BR11 & - & - & - & 20.3 & 18.5 & 10.8 & 19.8 & 28 \\
BRRI dhan32 & - & - & - & 34.8 & 33.0 & 26.0 & 34.0 & 33.0 \\
LSD (1\%) & & & \multicolumn{7}{c}{14.9} & & & \\
CV (\%) & & & & & & & & \\
\hline
\end{tabular}

Plant dry matter measured at 30-day after termination of submergence was minimum at early stages of seedling, which increased gradually with the age of seedling (Table 3). All the varieties 
produced higher dry matter between 40 and 45 -day-old seedlings. At all the seedling ages, the dry matter was significantly higher in FR13A than the remaining varieties. It appeared here that higher plant dry matter might contribute to better recovery and hence tolerance against submergence.

Table 3. Dry matter production (g/5 plants) at 30 days after drainage of water of four rice varieties as affected by age of seedling.

\begin{tabular}{lcccccccc}
\hline Varieties & \multicolumn{7}{c}{ Seedling age (days) } \\
\cline { 2 - 8 } & 10 & 15 & 20 & 25 & 30 & 35 & 40 & 45 \\
\hline FR13A & - & - & 8.80 & 8.90 & 11.25 & 9.10 & 15.30 & 14.70 \\
BR6110-10-2-1 & - & - & - & 3.28 & 4.35 & 2.98 & 5.28 & 6.40 \\
BR11 & - & - & - & 3.73 & 3.30 & 3.23 & 4.78 & 7.38 \\
BRRI dhan32 & - & - & - & 4.88 & 5.30 & 6.10 & 9.33 & 8.33 \\
LSD (1\%) & & & & & 2.48 & & & \\
CV (\%) & & & & & & & & \\
\hline
\end{tabular}

Plant height during recovery was not affected in FR13A (Table 4). More or less similar plant height $(81.2-86.8 \mathrm{~cm})$ was observed in all the seedling age in FR13A. But in other varieties, the parameter was significantly reduced by the seedling age. Plant height varied from 46.6 to $61.5 \mathrm{~cm}$, 42.4 to $60.0 \mathrm{~cm}$ and 56.3 to $69.7 \mathrm{~cm}$ in BR6110-10-2-1, BR11 and BRRI dhan32, respectively.

Table 4. Plant height $(\mathrm{cm})$ at 30 days after drainage of water as affected by age of seedling in four rice varieties.

\begin{tabular}{lcccccccc}
\hline Varieties & \multicolumn{7}{c}{ Seedling age (days) } \\
\cline { 2 - 8 } & 10 & 15 & 20 & 25 & 30 & 35 & 40 & 45 \\
\hline FR13A & - & - & 82.4 & 81.2 & 85.7 & 86.2 & 84.0 & 86.8 \\
BR6110-10-2-1 & - & - & - & 50.8 & 51.0 & 46.6 & 61.5 & 61.5 \\
BR11 & - & - & - & 52.4 & 42.4 & 47.3 & 53.6 & 60.0 \\
BRRI dhan32 & - & - & - & 60.3 & 56.3 & 61.0 & 68.0 & 69.7 \\
LSD (1\%) & & & & & 8.0 & & & \\
CV (\%) & & & & & & & & \\
\hline
\end{tabular}

Recovery score was made based on the attributes like tiller number, dry matter accumulation, and plant height. The variety FR13A and BRRI dhan32 had the lowest recovery score (1) indicating better recovery at all seedling age (Table 5). But, BR6110-10-2-1 recovered better at 45 days of seedling age and BR11 at 25, 40 and 45 days of seedling age. It was also reported that little better tolerance and recovery efficiency was exhibited in 60-day-old seedling than that in 30-day-old seedling both in BR11 and BR23 (BRRI 1991).

Table 5. Recovery score at 30 days after drainage of water as affected by age of seedling in four rice varieties.

\begin{tabular}{|c|c|c|c|c|c|c|c|c|}
\hline \multirow[t]{2}{*}{ Varieties } & \multicolumn{8}{|c|}{ Seedling age (days) } \\
\hline & 10 & 15 & 20 & 25 & 30 & 35 & 40 & 45 \\
\hline FR13A & 9.0 & 9.0 & 1.0 & 1.0 & 1.0 & 1.0 & 1.0 & 1.0 \\
\hline BR6110-10-2-1 & 9.0 & 9.0 & 9.0 & 4.3 & 3.5 & 4.5 & 3.5 & 2.0 \\
\hline BR11 & 9.0 & 9.0 & 9.0 & 2.0 & 7.5 & 7.0 & 2.0 & 1.0 \\
\hline BRRI dhan32 & 9.0 & 9.0 & 9.0 & 1.0 & 1.0 & 1.0 & 1.0 & 1.0 \\
\hline LSD (1\%) & \multicolumn{8}{|c|}{2.6} \\
\hline $\mathrm{CV}(\%)$ & \multicolumn{8}{|c|}{31.0} \\
\hline
\end{tabular}


Soluble sugar and starch content were determined separately in each variety of rice at different ages of seedling. The sugar level of plant tissue was generally higher before submergence which decreased markedly due to submergence (Fig. 4A). Irrespective of variety, with the increase of seedling age soluble sugar increased. The positive relationship between amount of carbohydrate in plant parts and submergence tolerance was reported by many researchers (Panda et al. 2008, Chaturvedi et al. 1993). The sugar level in FR13A was the highest both before and after submergence. Compared to FR13A, the sugar content of other varieties was lowered, both before and after submergence and followed almost similar pattern of increase. Panda et al. (2008) observed that the tolerant cultivar FR13A possessed $1.9-2.0$ and $3.2-3.7$ fold more nonstructural carbohydrate content before and after submergence compared to the susceptible cultivar IR42 and it had better capability to restore its photosynthetic capacity during post-submergence period.
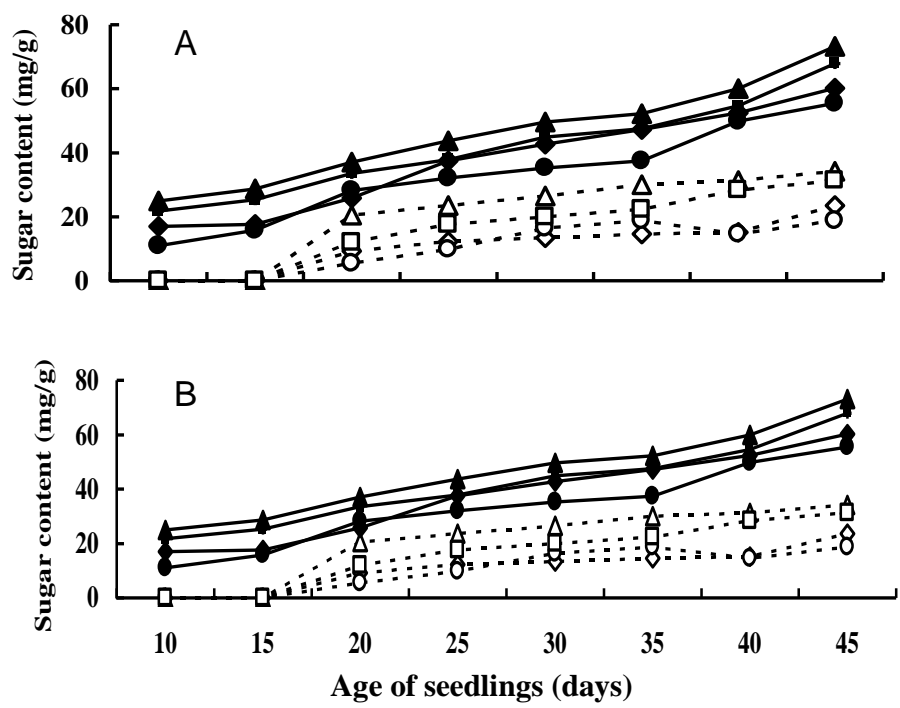

Fig. 4. Sugar (A) and starch (B) content of four rice varieties before and after ten days submergence. (Before submergence - $\boldsymbol{\Delta}$-FR13A, - $\bullet$ - BR11, - $\bullet$ - BR6110-10-2-1, -m- BRRI dhan-32; after submergence -- $\Delta$-FR13A, --৩-- BR6110-10-2-1, --O-- BR11, --口--BRRI dhan32).

The amount of carbohydrate present in a plant during the period of submergence is directly related to submergence tolerance (Chaturvedi et al. 1993). Sarkar et al. (1999) reported that nonstructural carbohydrate percentage showed maximum direct effect on survival percentage of submerged rice seedling. Das et al. (2005) suggested that carbohydrates maintained by the plant after submergence, being the result of both initial level, and the level used during submergence, is more important for survival.

Pre-submergence starch level did not show any marked variation up to 20-day-old seedlings in tested varieties (Fig. 4B). Beyond that seedling age, the variety FR13A distinctly maintained the highest starch level throughout the subsequent stages. Due to submergence, starch level decreased in all the varieties. Here FR13A also maintained higher starch level. After termination of submergence, the difference of starch level between FR13A and BR11 were larger at all seedling age compared to those under non-submerged condition. The results indicate that the extent of 
starch depletion was smaller in FR13A due to submergence (Fig. 5). The maintenance of higher starch rate appeared to contribute better survivality and recovery ability in FR13A. Similar observation was found by Chaturvedi et al. (1993). Submergence-tolerant varieties of rice tend to accumulate more starch in their stem sections than do susceptible varieties and they experience less carbohydrate depletion after submergence (Panda et al. 2008). Slow reduction rate in tolerant genotypes makes the substrate available for recover of growth after releasing the submergence. Mazaredo and Vergara (1982) also reported that there was correlation between submergence tolerance and the residual carbohydrate content after submergence treatment for six days $(\mathrm{r}=$ 0.6841 ) but not before treatment which indicated that the survival and rapid recovery of plants depended on the amount of carbohydrate available after submergence.

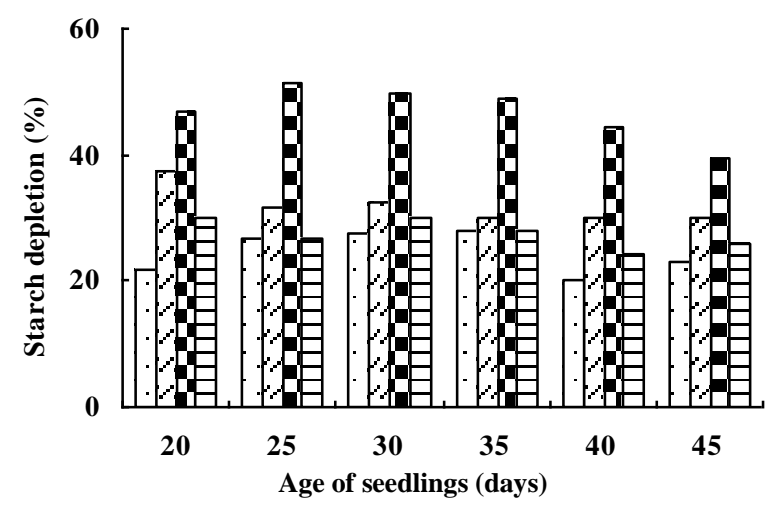

Fig. 5. Rate of starch depletion of four rice varieties at different seedling age. . (口FRI3A, $\square$ BR6110-10-2-1, B BR11, घ BRRI dhan 32).

From this study it may be concluded that genotypic variation in submergence tolerance is contributed by the seedling age and starch depletion rate in rice. The smaller rate of starch depletion during submergence as well as maintenance of higher level of starch appeared to contribute to better survival and recovery in FR13A.

\section{References}

Adkins S.W., T. Shiraishi and J.A. McComb. 1988. A new glasshouse method for experimental submergence of rice plants. In: Proceedings of the 1987 International Deepwater Rice Workshop, S.J. Banta, G.S. Argosino (Eds), pp. 311-318. IRRI, Los Banos.

Bangladesh Rice Research Institute (BRRI). 1984. Annual Report for 1980. Gazipur, Bangladesh. 187 pp.

Bangladesh Rice Research Institute (BRRI). 1991. Annual Report for 1988. Gazipur, Bangladesh. 325 pp.

Chaturvedi G.S., C.H. Misra, O.N. Singh, C.B. Pandey, V.P. Yadev, A.K. Singh, J.L. Dwivedi, B.B. Singh and R.K. Singh. 1993. Physiological basis and screening for tolerance for flash flooding. In: Rainfed lowland rice - agricultural research for high risk environments, T.L. Setter, K.T. Ingram, T.P. Tuog (Eds), pp. 78-96. IRRI, Los Banos.

Das K.K., R.K. Sarkar and Abdelbagi M Ismail. 2005. Elongation ability and non-structural carbohydrate levels in relation to submergence tolerance in rice. Plant Sci. 168: 131-136.

Gomosta A.R., M.M. Hossain and M.Z. Haque.1982. Screening methods for submergence tolerance in rice in Bangladesh. In: Proceeding of the 1981 International Deepwater Rice Workshop, S.K. De Datta, W.G. Rockwood, E.P. Cervantes (Eds), pp. 243-248. IRRI, Los Banos. 
Greenway H. and T.L. Setter. 1996. Is there anaerobic metabolism in submerged rice plants? A view point. In: Physiology of stress tolerance in rice, V.P. Sing, R.K. Sing, B.B. Sing, R.S. Zeigler (Eds), pp. 1130. NDUAT and IRRI. Manila.

Hossain M.M., A.R. Gomosta and M.Z. Haque. 1983. Submergence tolerance of four Transplanted Aman rice varieties. Bangladesh J. Agric. 8(1-4): 37-43.

Islam M.S., M.Z. Haque, M.A. Jabber, A.K. Basak and N.K. Paul. 1997. Effect of simulated rainfall at reproductive to ripening stages on the growth and yield of transplant aman rice. Ann. Bangladesh Agric. 7(2): 105-110.

Ito O., E. Ella and N. Kawano. 1999. Physiological basis of submergence tolerance in rainfed lowland rice ecosystem. Field Crops Res. 64: 75-90.

Mazaredo A.M. and B.S. Vergara. 1982. Physiological differences in rice varieties tolerant of and susceptible to complete submergence. In: Proceedings of the 1981 International Deepwater rice workshop, S.K. De Datta, W.G. Rockwood, E.P. Cervantes (Eds), pp. 327-341. IRRI, Los Bonos.

Mohanty B. and B. Ong. 2003. Contrasting effects of Submergence in light and dark on pyruvate decarboxylase activity in roots of rice lines differing in submergence tolerance. Ann. Bot. 91: 291300.

Panda D., S.G. Sharma and R.K. Sharkar. 2008. Chlorophyll fluorescence parameters, $\mathrm{CO}_{2}$ photosynthetic rate and regeneration capacity as a result of complete submergence and subsequent re-emergence in rice (Oryza sativa L.). Aquatic Bot. 88: 127-133.

Pande H.K., B.N. Mittra and B.C. Ghosh. 1979. Flood susceptibility of semi dwarf rices and investigation on their suitability for low lying areas. In: Proceedings of the 1978 International Deepwater Rice Workshop, T.R. Hargrove, G.S. Argosino (Eds), pp. 185-195. IRRI, Los Banos.

Sarkar R.K., Sahu, R.K. Suriya, A.V. Rao and R.N. De. 1999. Correlation and path analysis of certain morpho-physiological characters with submergence tolerance in rainfed lowland rice. Ind. J. Plant Physio. 4: 346-348.

Sarkar R.K., J.N. Reddy, S.G. Sharma and Abdelbagi M Ismail. 2006. Physiological basis of submergence tolerance in rice and implications for crop improvement. Curr. Sci. 91(7): 899-906.

Sauter M. 2000. Rice in deepwater. 'How to take heed against a sea of troubles'. Naturwissenschaften 87: 289-303.

Supapoj N., D. HilleRisLambers, C. Boonwite and S. Karin. 1979. Potential for improving submergence tolerance in rainfed lowland rice. In: Rainfed lowland rice. Selected papers from the 1978 international rice research conference, W.G. Rockwood, G. Argosino, E. Cervantes (Eds), pp. 165-174. IRRI, Los Banos.

Yoshida S., D.A. Forna, J.H. Cock and K.A. Gomez. 1976. Laboratory manual for physiological studies of rice. IRRI, Los Banos. pp 83.

Zeigler R.S. and D.W. Puckridge. 1995. Improving sustainable productivity in rice-based rain fed lowland systems of south and Southeast Asia. Geo. J. 35: 307-324.

(Manuscript received on 26 January 2009; revised on 12 May 2010) 